\title{
The Influence of Silicon on Components of Resistance to Blast in Susceptible, Partially Resistant, and Resistant Cultivars of Rice
}

\author{
K. W. Seebold, T. A. Kucharek, L. E. Datnoff, F. J. Correa-Victoria, and M. A. Marchetti
}

First and second authors: Plant Pathology Department, University of Florida-IFAS, Gainesville 32611; third author: Plant Pathology Department, University of Florida-IFAS, Everglades Research and Education Center, Belle Glade 33430; fourth author: Centro Internacional de Agricultura Tropical, A.A. 6713, Cali, Colombia; and fifth author: U.S. Department of Agriculture-Agricultural Research Service, Beaumont, TX 77713.

Accepted for publication 11 August 2000.

\begin{abstract}
Seebold, K. W., Kucharek, T. A., Datnoff, L. E., Correa-Victoria, F. J., and Marchetti, M. A. 2001. The influence of silicon on components of resistance to blast in susceptible, partially resistant, and resistant cultivars of rice. Phytopathology 91:63-69.

The application of silicon ( $\mathrm{Si}$ ) fertilizers reduces the severity of blast, caused by Magnaporthe grisea, in irrigated and upland rice; however, little research has been conducted to examine the epidemiological and etiological components of this reduction. Four cultivars of rice with differential susceptibilities to race IB-49 of M. grisea were fertilized with three rates of a calcium silicate fertilizer and inoculated with the pathogen

to test the effects of $\mathrm{Si}$ on the following components of resistance to blast: incubation period, latent period, infection efficiency, lesion size, rate of lesion expansion, sporulation per lesion, and diseased leaf area. For each cultivar, the incubation period was lengthened by increased rates of $\mathrm{Si}$, and the numbers of sporulating lesions, lesion size, rate of lesion expansion, diseased leaf area, and number of spores per lesion were reduced. Lesion size and sporulation per lesion were lowered by 30 to $45 \%$, and the number of sporulating lesions per leaf and diseased leaf area were significantly reduced at the highest rate of $\mathrm{Si}$. The net effect of $\mathrm{Si}$ on these components of resistance is an overall reduction in the production of conidia on plants infected with $M$. grisea, thereby slowing the epidemic rate of blast
\end{abstract}

Rice blast, caused by Magnaporthe grisea (Hebert) Barr, is the most destructive fungal disease of rice, particularly in temperate, irrigated rice and tropical upland rice $(3,24,37)$. The pathogen can infect all above-ground parts of the rice plant, but is most common on leaves causing leaf blast during the vegetative stage of growth or neck nodes and panicle branches during the reproductive stage causing neck blast $(3,4,37)$. Although not as damaging as neck blast, leaf blast can be severe in tropical upland rice and can significantly reduce leaf area and yields $(1,29)$.

Cultivars of rice with either complete or partial resistance to blast are utilized routinely to control the disease $(3,4,11,19,24)$. Complete resistance, which corresponds to van der Plank's (38) vertical resistance, is characterized by a hypersensitive response to infection and tends to be short-lived in nature due to shifts in populations of pathogenic races of $M$. grisea $(3,19)$. This is a result of natural variability in populations of $M$. grisea or a failure to select breeding materials resistant to pathogen populations encountered in commercial fields $(10,11,29)$. Cultivars of rice with partial resistance to blast are highly effective in controlling the disease, especially in tropical lowland environments (5). Partial resistance, also referred to as horizontal or rate-reducing resistance, is controlled in plants by multiple genes that have quantitative effects against the pathogen, and is generally more durable $(19,25,38)$. Partial resistance, as defined by Parlevliet $(25)$, is a type of incomplete resistance characterized by reduced production of spores despite a susceptible reaction by the host to the pathogen. The overall effect of fewer spores is a reduction in the rate of epidemic progress. Cultivars of rice with complete resistance

Corresponding author: L. E. Datnoff; E-mail address: leda@gnv.ifas.ufl.edu

Florida Agricultural Experiment Station Journal Series No. R-07096

Publication no. P-2000-1115-01R

(C) 2001 The American Phytopathological Society against certain races of $M$. grisea may also possess some degree of partial resistance $(28,44)$.

Rate-reducing resistance to plant diseases is affected by various components that limit the production of spores or secondary inoculum by a given pathogen (25). Reductions in the rate of progress of an epidemic in plants with partial resistance to various pathogens have been associated with a lengthened latent period (period between inoculation and sporulation), reduced infection efficiency (the number of sporulating lesions per unit of inoculum), reduced lesion size (length or diameter), retarded rate of lesion expansion, shortened period of sporulation, and reduced number of spores per lesion $(9,16,20,22,25,26,28,30,36,41)$. Roumen (28) found no differences in latent period or incubation period (the period between inoculation and appearance of symptoms) of $M$. grisea among three cultivars of rice with varying degrees of partial resistance to rice blast. However, cultivars expressing high levels of partial resistance had fewer sporulating lesions per leaf and smaller sporulating area per lesion than cultivars with lower or no resistance to blast. Other researchers indicate that some variability in latent period exists between cultivars of rice with partial resistance to blast $(7,27,42)$. Yeh and Bonman (42) reported that sporulation from individual lesions was significantly greater for blast-susceptible cultivars than for partially resistant and resistant cultivars.

The application of silicon $(\mathrm{Si})$ to soils deficient in $\mathrm{Si}$ reduces the severity of rice blast in both irrigated and upland rice (1214,33). Previous reports $(32,35)$ suggest that Si reduces the rate of progress of blast epidemics, and that $\mathrm{Si}$ influences the expression of partial resistance to blast. However, little is known about the effects of fertilization with $\mathrm{Si}$ on the individual components of resistance to rice blast. Volk et al. (40) demonstrated that increased levels of $\mathrm{Si}$ in leaf tissue of rice decreased the number of sporulating blast lesions per leaf, indicating that $\mathrm{Si}$ affects the infection efficiency of the blast pathogen. Si affects several components of resistance to powdery mildew of cucumber, caused by 
Sphaerotheca fuliginea. Menzies et al. (20) found that infection efficiency, colony size, and germination of conidia were reduced when cucumbers were grown in nutrient solutions with high concentrations of Si.

The purpose of this study was to evaluate the effects of Si applied at several rates on the components of resistance to rice blast, and to determine if these effects were similar in cultivars with no resistance, partial resistance, or complete resistance to rice blast.

\section{MATERIALS AND METHODS}

Experiments on components of resistance to rice blast were conducted in greenhouses at the University of Florida at Gainesville. Rice cvs. M201, Rosemont, Lemont, and Katy were chosen to represent a range of resistance types to race IB-49 of $M$. grisea. 'M201' has no known major or minor genes for resistance to race IB-49 and is completely susceptible. 'Rosemont' and 'Lemont' are partially resistant to race IB-49, and 'Katy' is completely resistant. The following components of resistance were evaluated on each cultivar: incubation period, latent period, relative infection efficiency, lesion size, total area of lesions per leaf, spore number per lesion, and daily rate of lesion expansion.

The soil used was a Si-deficient Histosol (Terra Ceia muck), obtained from the New Hope Sugar Corp. near Belle Glade, FL, with a Si content of approximately $5.0 \mathrm{mg} \mathrm{liter}^{-1}$. Styrofoam cups $(10.5 \times 17 \mathrm{~cm})$ were filled with soil and amended with calcium silicate (Vansil W-20; R.T. Vanderbilt, Norwalk, CT) at rates equivalent to $0,2,5$, and 10 metric tons $(\mathrm{T}) \mathrm{ha}^{-1}$. Available, soluble Si from Vansil W-20 was approximately 20\%. Calcium car-
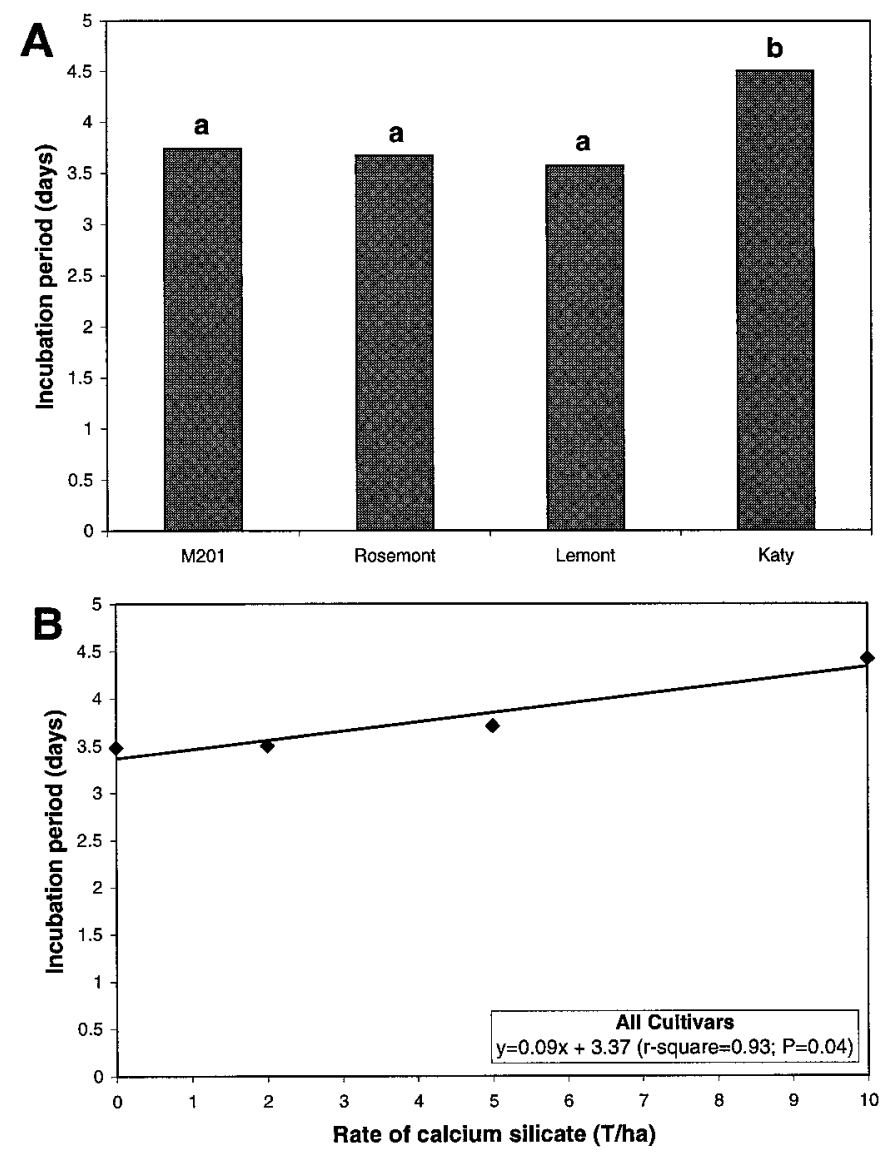

Fig. 1. Effects of calcium silicate on incubation period of Magnaporthe grisea for rice cvs. M201, Rosemont, Lemont, and Katy. A, Mean incubation period of $M$. grisea for each cultivar averaged across rates of calcium silicate. Bars with the same letter do not differ significantly at $P=0.05$, as determined by Fisher's protected LSD test. B, The relationship between incubation period and rate of calcium silicate averaged across means for all cultivars. bonate was added to cups treated with 0,2 , and $5 \mathrm{~T} \mathrm{ha}^{-1}$ of calcium silicate to equilibrate the amount of calcium in each treatment with the amount present in the $10 \mathrm{~T} \mathrm{ha}^{-1}$ treatment $(1.3 \mathrm{~g}$ per cup). Seeds of each cultivar were germinated in petri plates and seeded at a rate of five seedlings per cup. Approximately 10 days after planting, each cup was thinned to two plants. No modifications were made to the cups to allow for drainage, and plants were kept under flooded conditions until time of inoculation. The experiment was conducted as a completely randomized design with 16 treatments and three replications. All experiments were repeated three times, with the exception of the lesion size and sporulation studies (repeated twice).

Inoculations were made at dusk on or around the time of emergence of the sixth or seventh leaf from the bottom of the main tiller (approximately 35 days after planting) by an aerosol sprayer (Crown Spra-Tool; Fisher Scientific Co., Pittsburgh). Twenty milliliters of a conidial suspension were applied as a fine mist to the two plants per cup. Inoculum was obtained as follows. Isolate 793 (IB49) of $M$. grisea was grown on $20 \%$ V8 agar to produce inoculum. On the day of inoculation, a petri plate containing a sporulating culture of isolate 793 was flooded with $5 \mathrm{ml}$ of distilled water and scraped with a rubber policeman. The resulting suspension was homogenized and adjusted to a concentration of $1.2 \times 10^{4}$ conidia $\mathrm{ml}^{-1}$. Gelatin was added $(1 \%, \mathrm{wt} / \mathrm{vol})$ to the conidial preparation to aid in adhesion to leaf surfaces. Inoculated plants were transferred to a mist chamber and maintained at $100 \%$ relative humidity for $15 \mathrm{~h}$. Plants were removed and kept dry until the appearance of symptoms of blast. When symptoms appeared, each plant was placed in a polyethylene bag, and leaves were wetted with a hand mister to induce sporulation. Bagged plants were maintained in an incubation chamber at $28^{\circ} \mathrm{C}$ for the duration of the experiments.

Resistance to $M$. grisea increases as leaf age of the rice plant increases; therefore, leaves five and six on the main tiller of each plant were used to insure that leaves used to evaluate components of resistance to blast were of the same age class. Incubation period, latent period, and lesion expansion were determined on attached leaves. Incubation period was scored as the date of appearance of necrotic flecks (initial lesions) on marked leaves. Five randomly chosen lesions per cup were examined for the presence of conidia with a hand held microscope $(\times 100)$ every $24 \mathrm{~h}$ to determine the beginning of sporulation. Latent period for each treatment was rated as the time at which $60 \%$ of the lesions, or three of the five tested, began to sporulate $\left(\mathrm{LP}_{60}\right)$. The daily rate of lesion expansion was calculated by employing a digital caliper to measure the length (millimeter) of five emerging lesions on marked leaves on the first day of emergence, followed by daily measurements that ended when expansion ceased. Depending upon the treatment, fewer than five lesions were evaluated on resistant cv. Katy due to low lesion numbers.

Sporulation per lesion was determined in the following manner. Five sporulating lesions per pot were excised and each placed in a scintillation vial containing $1 \mathrm{ml}$ of a $(1 \%, \mathrm{wt} / \mathrm{vol})$ solution of copper sulfate plus a small drop of a (1\%, vol/vol) solution of Triton X-100 (Rohm and Haas Co., Philadelphia). Copper sulfate was added to the suspension to prevent germination of the conidia. These were then stored at $3^{\circ} \mathrm{C}$ until evaluation. Vials were agitated vigorously with a Vortex Genie 2 (Scientific Industries Inc., Bohemia, NY) for 2 min. Following agitation, 10 samples were drawn from each vial and the number of conidia were counted with a hemacytometer and mathematically related to the number of conidia per milliliter. Because lesion size varied among lesions for a given treatment and between lesions from different treatments, the number of conidia per milliliter was adjusted to reflect size of lesion as follows. After counting conidia, excised lesions were removed from scintillation vials and fixed to a sheet of paper. Each group of five lesions (from each treatment) was digitally photographed (Canon RE-650 Mk II Video Visualizer; Canon, 
Lake Success, NY) and captured on a personal computer with a TARGA+ frame grabber (Truevision Inc., Indianapolis). Area of lesions (square millimeters) was determined by analyzing stored images (Sigma Scan Pro version 2.0; Jandel Scientific Software, San Rafael, CA). The number of conidia from a given lesion was divided by the corresponding lesion size to obtain the number of conidia per square millimeter of lesion. Due to a lack of lesions, between one and four were evaluated for 'Katy', depending upon the rate of calcium silicate applied.

When all lesions had emerged on marked leaves and had reached maximum size, two leaves from each cup were removed and fixed, with double-sided tape, to sheets of paper $(21.6 \times 28 \mathrm{~cm})$. Leaves from each treatment were photographed as described previously. Leaf area, number of sporulating lesions, size of sporulating lesions (measured as length of the longest axis of each lesion), and leaf area with lesions was estimated from stored digital images. Sporulation of fully expanded lesions was verified prior to photography of each leaf with a hand-held microscope $(\times 100)$. The number of sporulating lesions was divided by total leaf area to obtain a relative number of lesions per square millimeter of leaf.

Approximately $10 \mathrm{~g}$ of leaf tissue was harvested from each treatment and dried for analysis of Si content. Dried leaves were ground in a Wiley mill (Thomas Scientific, Swedesboro, NJ) to pass through a 40-mesh screen. Ground tissue was assayed according to the autoclave-induced digestion procedure of Elliot and Snyder (15). Percent Si of tissue was determined from the digestate by automated colorimetric analysis.

Data were analyzed by analysis of variance and linear regression where appropriate with statistical analysis software (Windows version 6.12; SAS Institute, Cary, NC). Log transformation was employed in cases where data were not normally distributed. Significance was determined at $P \leq 0.05$, unless otherwise stated.

\section{RESULTS}

The interaction between main effects was not significant for the components of resistance tested. Except for infection efficiency and diseased leaf area, means are presented by cultivar, averaged across rate of calcium silicate, and by rate of calcium silicate, averaged across cultivar.

Incubation and latent periods. Incubation period ranged from 3.5 to 4.5 days, depending upon the cultivar (Fig. 1A). No significant differences in incubation were found among 'M201' (susceptible), 'Rosemont' (partially resistant), and 'Lemont' (partially resistant); however, the incubation period of resistant cv. Katy was significantly longer than for the other cultivars (Fig. 1A). Regardless of cultivar, incubation period increased in a linear manner as the rate of calcium silicate increased $(P \leq 0.05)$ (Fig. 1B). The lengthened incubation period associated with higher rates of $\mathrm{Si}$ was more pronounced for 'Katy' than for the remaining cultivars (data not shown). Latent period ranged from 6.47 to 6.77 days and did not differ between cultivars (data not shown). No linear relationship was found between latent period and rate of calcium silicate for any of the cultivars tested.

Relative infection efficiency. Relative infection efficiency of M. grisea, determined as the number of sporulating lesions per square millimeter of leaf area, was highest on 'M201' and 'Rosemont' and lowest on 'Katy' (Fig. 2A). 'Lemont' had 92\% fewer sporulating lesions per leaf area than 'M201'. Relative infection efficiency was $97 \%$ lower on 'Katy' compared with 'M201' and was significantly lower when compared with 'Rosemont' or 'Lemont', except at the highest rate of Si. The number of sporulating lesions counted on 'Lemont' treated with $10 \mathrm{~T} \mathrm{ha}^{-1}$ was not significantly different from 'Katy' (Fig. 2C). The relationship between number of sporulating lesions per leaf area and rate of calcium silicate was linear for all cultivars (Fig. 2B). There was no significant change in the number of sporulating lesions on 'Katy' at any rate of calcium silicate (Fig. 2C); how- ever, the means for 'Katy' are included in the analysis of main effect for rate of calcium silicate due to a lack of interaction between main effects. When the rate of calcium silicate was increased from 0 to $10 \mathrm{~T} \mathrm{ha}^{-1}$, the number of sporulating lesions per leaf area decreased by $71 \%$ on 'M201', 'Rosemont', and 'Lemont' (Fig. 2B and C).

Lesion length. The average length of blast lesions was longer on 'M201' than on 'Rosemont', 'Lemont', and 'Katy' (Fig. 3A). Lesion length did not differ significantly between 'Rosemont' or 'Lemont', and lesion length was shortest for 'Katy' (Fig. 3A). Considering all cultivars, lesion length was reduced by approximately $40 \%$ when the rate of $\mathrm{Si}$ increased from 0 to $10 \mathrm{~T} \mathrm{ha}^{-1}$ $(P \leq 0.08)$ (Fig. 3B).

Lesion expansion. Regardless of the rate of $\mathrm{Si}$, the daily rate of lesion expansion was significantly higher on 'M201' than on
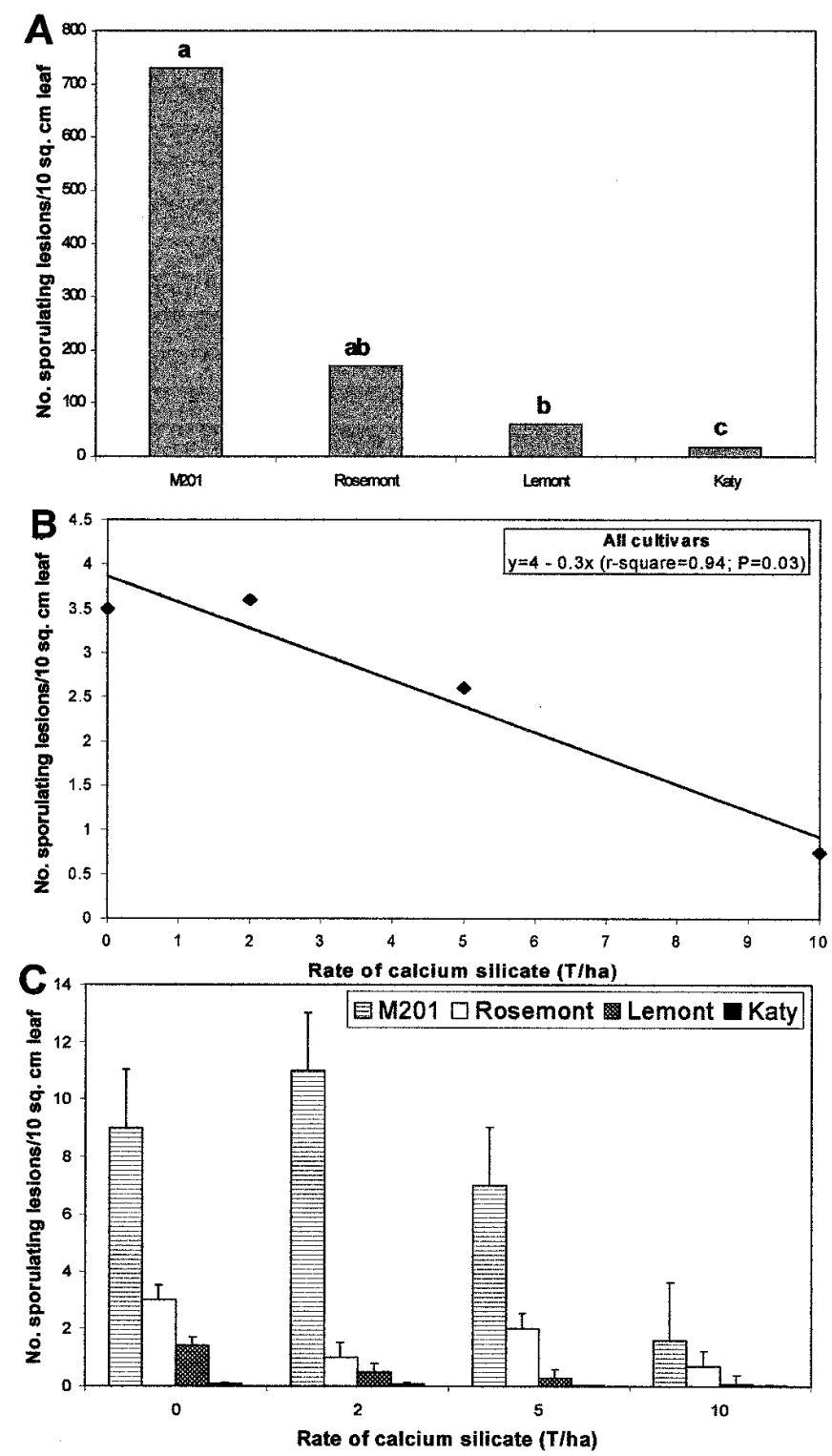

Fig. 2. Effects of calcium silicate on the number of sporulating lesions of blast (relative infection efficiency) for rice cvs. M201, Rosemont, Lemont, and Katy. A, Mean number of sporulating lesions per square millimeter of leaf for each cultivar averaged across rate of calcium silicate. Bars with the same letter in $\mathbf{A}$ do not differ significantly at $P=0.05$ as determined by Fisher's protected LSD test performed on log-transformed values. B, The relationship between the number of sporulating lesions per square millimeter of leaf and rate of calcium silicate, averaged across means for all cultivars. C, The number of sporulating lesions per square millimeter of leaf for each cultivar and rate of calcium silicate. Bars represent standard errors of means. 
'Rosemont', 'Lemont', or 'Katy' (Fig. 4A). Rate of lesion expansion was 42 and $59 \%$ slower on 'Rosemont' and 'Lemont', respectively, compared with 'M201' and did not differ significantly between these two cultivars. Rate of lesion expansion was slower on 'Katy' than on 'Rosemont', 'Lemont', or 'M201' (Fig. 4A). For all cultivars, rate of lesion expansion decreased from 0.8 to $0.43 \mathrm{~mm}$ per day $(49 \%)$ as the rate of calcium silicate increased from 0 to $10 \mathrm{ha}^{-1}(P \leq 0.07)$ (Fig. 4B).

Lesion area per leaf. Lesion area per leaf (i.e. percent diseased leaf area) was significantly higher on 'M201' and 'Rosemont' than on 'Lemont' or 'Katy' (Fig. 5A), although there was no difference in lesion area between 'Rosemont' or 'Lemont'. Cultivar Lemont had 63\% less diseased leaf area than 'M201' (Fig. 5A). Lesion area was 98\% smaller on 'Katy' than on 'M201'. For all cultivars except 'Katy', lesion area was reduced by approximately $80 \%$ as the rate of calcium silicate increased from 0 to $10 \mathrm{~T} \mathrm{ha}^{-1}$ (Fig. 5B and $\mathrm{C}$ ). There was no change in percent diseased leaf area for 'Katy' at any rate of calcium silicate (Fig. 5C). Because the interaction between cultivar and rate of calcium silicate was not significant, the means for 'Katy' are included in the analysis of the main effect for rate of calcium silicate.

Number of spores per square millimeter of lesion. The number of spores per square millimeter of lesion was different among all four cultivars (Fig. 6A). Sporulation per square millimeter of lesion was over three times higher on 'M201' than on 'Rosemont' and 10 times higher than 'Lemont'. Only seven spores per square millimeter was recovered from lesions on 'Katy' (Fig. 6A). The relationship between rate of calcium silicate and the number of spores per square millimeter of lesion was linear for all cultivars,
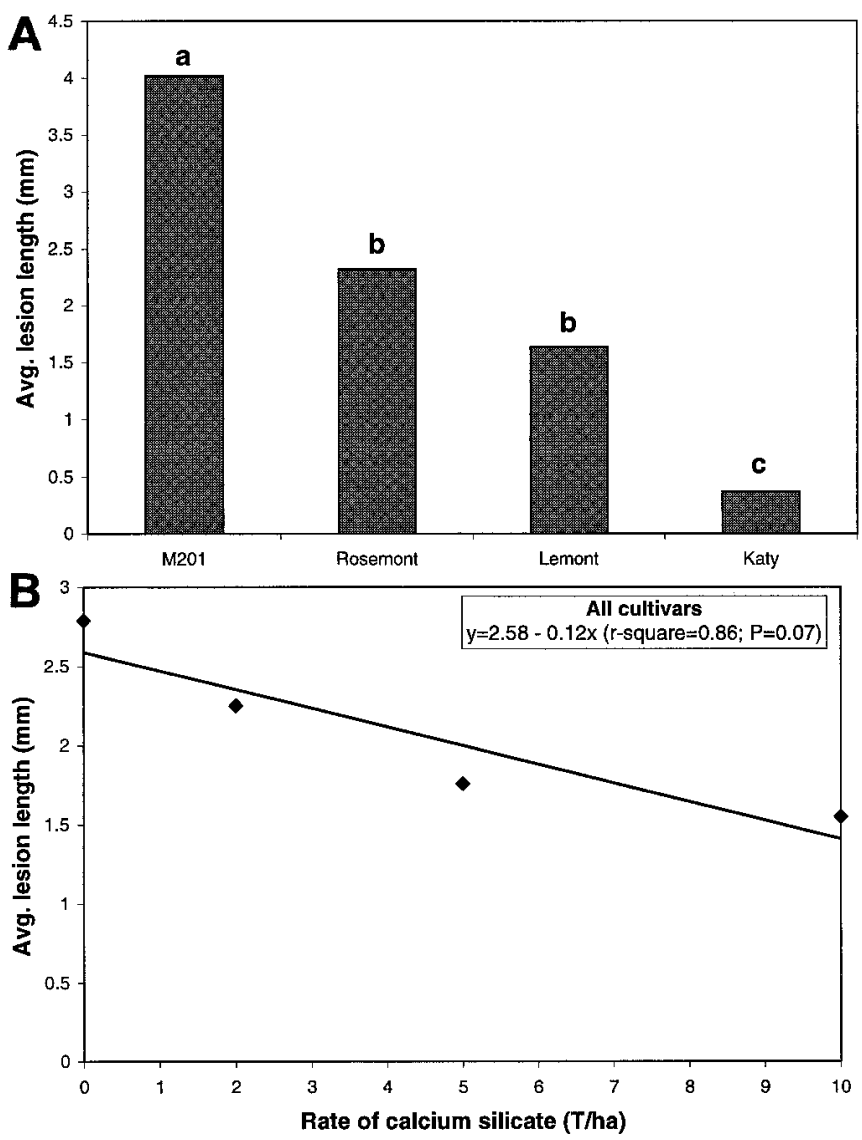

Fig. 3. Effects of calcium silicate on length of blast lesions for rice cvs. M201, Rosemont, Lemont, and Katy. A, Average lesion size for each cultivar averaged across rates of calcium silicate. Bars with the same letter do not differ significantly at $P=0.05$ as determined by Fisher's protected LSD test. $\mathbf{B}$, The relationship between lesion size and rate of calcium silicate, averaged across means for all cultivars. but significant only at $P=0.10$ (Fig. 6B). Sporulation per square millimeter of lesion on all cultivars was reduced by $47 \%$ as the rate of calcium silicate increased from 0 to $10 \mathrm{~T} \mathrm{ha}^{-1}$. The lack of interaction between cultivar and rate of calcium silicate for the number of spores per square millimeter of lesion permitted the analysis of main effects only. Only 'M201' showed a decrease in spores per square millimeter of lesion as the rate of $\mathrm{Si}$ increased (data not shown).

Percentage of Si in leaf tissue. The concentration of Si in leaf tissue, in decagrams per kilogram did not differ significantly between 'M201', 'Rosemont', 'Lemont', or 'Katy', regardless of the rate of Si applied (Fig. 7); however, the percentage of Si in leaf tissue was increased by more than $60 \%$ in all cultivars as the rate of calcium silicate increased from 0 to $10 \mathrm{~T} \mathrm{ha}^{-1}$ (Fig. 7).

\section{DISCUSSION}

Silicon reduces the rate of progress $(r)$ of epidemics of leaf blast and increases the level of resistance to leaf blast on partially resistant and susceptible cultivars of rice $(32,34,35)$. The results of the present study are evidence that $\mathrm{Si}$ acts on several factors or components of resistance that limit the production of conidia on rice leaves infected by $M$. grisea. Although reports from Osuna-Canizalez et al. (23) and Volk et al. (40) describe the effects of Si on lesion number and size, the results herein represent the first attempt to characterize the interaction between $\mathrm{Si}$, host resistance, and multiple components of resistance to blast.

The component of resistance most affected by $\mathrm{Si}$ is relative infection efficiency (the number of sporulating lesions) and, to a
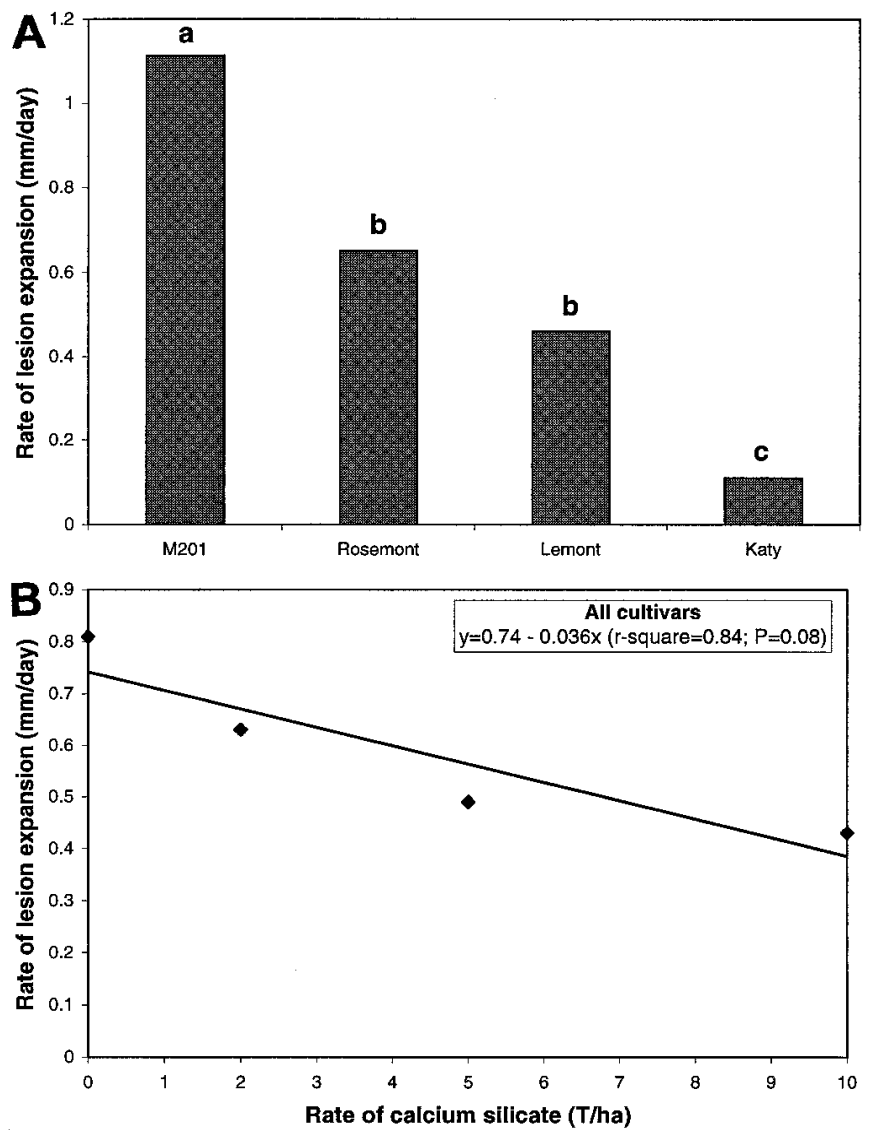

Fig. 4. Effects of calcium silicate on the daily rate of expansion of blast lesions for rice cvs. M201, Rosemont, Lemont, and Katy. A, The rate of expansion of blast lesions for each cultivar averaged across rates of calcium silicate. Bars with the same letter do not differ significantly at $P=0.05$ as determined by Fisher's protected LSD test. B, The relationship between rate of lesion expansion and rate of calcium silicate, averaged across means for all cultivars. 
lesser extent, lesion size and sporulation per lesion. By reducing relative infection efficiency, the number of sporulating lesions that can contribute inoculum for secondary cycles is curtailed, and reductions in size of lesions further limit production of inoculum. This is best illustrated by considering van der Plank's (39) basic infection rate $(R)$ and its influence on the production of inoculum. The basic infection rate is calculated as $R=N \times e$, where $N$ equals the number of conidia and $e$ equals the efficiency of those conidia in establishing infections that produce sporulating lesions. The overall effect on $R$ is a change in the production of inoculum. Reduced sporulation results in a depression of $r$.

Relative infection efficiency of $M$. grisea was greatly affected by cultivar and rate of calcium silicate in this study. Based upon the magnitude of response and statistical significance, relative infection efficiency was affected more by rate of Si than the other components tested in this study. These findings are consistent with previous reports that tissue levels of $\mathrm{Si}$ in blast-susceptible cultivars are associated with the number of blast lesions $(23,40)$. The
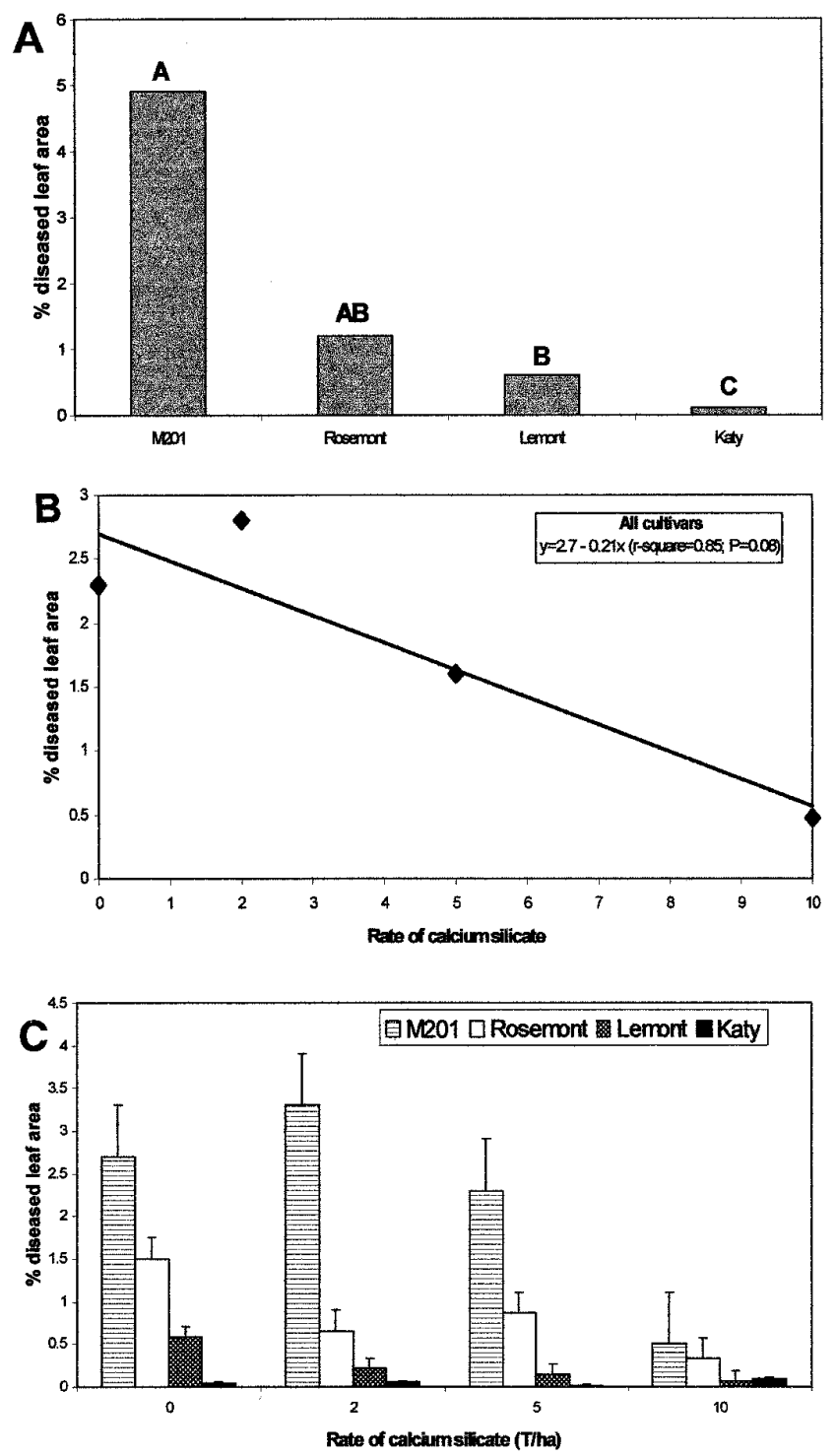

Fig. 5. Effects of calcium silicate on the percentage of leaf area with blast symptoms (percent diseased leaf area) for rice cvs. M201, Rosemont, Lemont, and Katy. A, The percent diseased leaf area for each cultivar averaged across rates of calcium silicate. Bars with the same letter do not differ significantly at $P=0.05$ as determined by Fisher's protected LSD test performed on log-transformed values. B, The relationship between percent diseased leaf area and rate of calcium silicate averaged across means for all cultivars. C, Effects on percent diseased leaf area for each cultivar and rate of calcium silicate. Bars represent standard errors of means. effect of $\mathrm{Si}$ on relative infection efficiency, as determined by the number of sporulating lesions, is apparent on partially resistant or susceptible cultivars and is rate-responsive. In the case of blastresistant 'Katy', the number of sporulating lesions found on plants that did not receive calcium silicate was near zero. Osuna-Canizalez et al. (23) also found no differences in the number of sporulating lesions between resistant cultivars grown in a solution containing $\mathrm{Si}$ and those that had not received $\mathrm{Si}$.
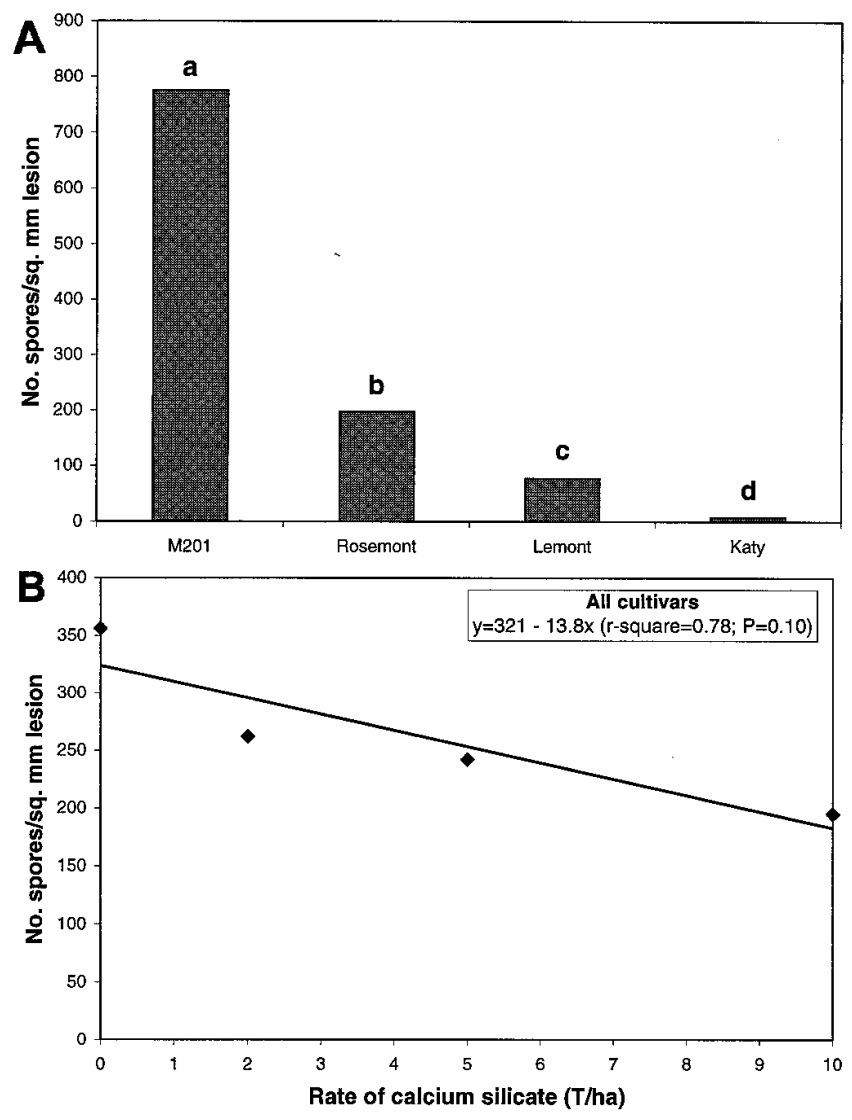

Fig. 6. Effects of calcium silicate on the sporulation of blast lesions for cvs. M201, Rosemont, Lemont, and Katy. A, The number of spores per square millimeter of lesion for each cultivar averaged across rates of calcium silicate. Bars with the same letter do not differ significantly at $P=0.05$ as determined by Fisher's protected LSD test performed on log-transformed values. B, The relationship between the number of spores per square millimeter of lesions and rate of calcium silicate averaged across means for all cultivars.

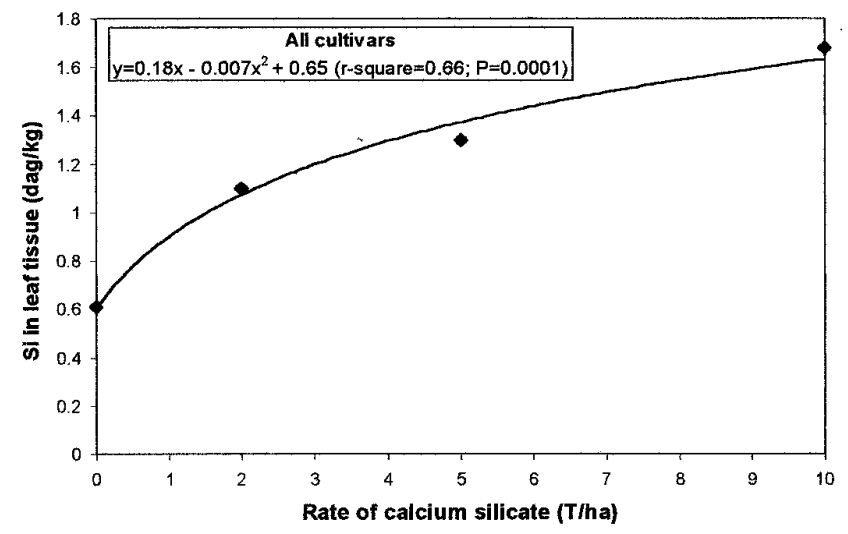

Fig. 7. Effects of calcium silicate on the concentration of silicon (Si) in leaf tissue for rice cvs. M201, Rosemont, Lemont, and Katy. Curve illustrates the relationship between $\mathrm{Si}$ content and rate of calcium silicate averaged across means for all cultivars. 
Differences among cultivars and rates of $\mathrm{Si}$ for lesion length could be influenced by the accumulation of $\mathrm{Si}$ in epidermal cells. Volk et al. (40) hypothesized that lesion size was reduced by organosilicon compounds in the walls of epidermal cells, and Inanaga et al. (17) demonstrated that $\mathrm{Si}$ forms complexes with organic compounds in these cells. However, it is possible that decreased size of lesions on Si-treated plants is a result of heightened induced resistance mechanisms within the host. Si increases the amount of pathogenesis-related defense compounds, such as phenolics, peroxidases, and chitinases, in plants other than rice when challenged with fungal pathogens $(6,8,21)$. In rice, the accumulation of phenolic compounds occurs at the margins of blast lesions following establishment of infection and is dependent upon the level of resistance of a given genotype (28). Formation of a necrotic margin around lesions is a defense response to infection, and it is possible that $\mathrm{Si}$ acts in some way to enhance this response. Histological and physiological studies on the infection process of $M$. grisea on rice are needed to determine the actual mechanisms of Si-mediated resistance to rice blast.

The effect of rate of $\mathrm{Si}$ on lesion length was less significant than for relative infection efficiency (number of sporulating lesions). Unlike relative infection efficiency, lesion length was reduced on all cultivars by an average of $46 \%$ with increasing rates of $\mathrm{Si}$. Therefore, the mechanism by which $\mathrm{Si}$ acts to reduce lesion size appears to compliment the resistance to blast expressed by the cultivars tested in this study. The rate of lesion expansion was closely associated with the length of lesions. Lesions caused by $M$. grisea are determinate in size and reached maximum size at roughly the same time for all cultivars and rates of Si (data not shown), resulting in measurements similar to those for length of lesion. Of these two components, lesion length appears to be a more important component of resistance to leaf blast than rate of lesion expansion because sporulation was not observed on lesions from any treatment until maximum size was reached. Lesion expansion is of more importance in pathosystems where lesions are indeterminate and continue to expand until host tissue is completely diseased, or nearly so (2).

The effect of $\mathrm{Si}$ on the number of conidia per lesion was not clear. Although a general decline in number of conidia was observed across all cultivars, an examination of means by cultivar shows that, in reality, sporulation per lesion area was reduced by Si on 'M201' only (data not shown). Despite having nearly the same content of Si in leaf tissue as 'M201', no change in sporulation occurred on 'Rosemont' or 'Lemont' at 0,5 , and $10 \mathrm{~T}$ of calcium silicate per hectare, and no conidia were recovered from lesions on 'Katy'. It is important to note that the total number of lesions available for estimation of number of conidia was smaller on partially resistant and resistant cultivars than on the susceptible cultivar, and the number decreased as the rate of Si increased. Thus, the small sample sizes and inherent resistance in some cultivars contributed to erratic estimates of the number of conidia per square millimeter of lesion. In the case of 'Katy', sporulating lesions were rare at any rate of Si. Sporulation per lesion is of less epidemiological importance than the reduction in lesion number.

Although an extended latent period has been identified as a significant component of resistance in several pathosystems $(9,18,22$, 30,41 ), no significant effect of $\mathrm{Si}$ on latent period of $M$. grisea was detected among cultivars in this study. The incubation period of $M$. grisea was significantly lengthened on all cultivars as the rate of $\mathrm{Si}$ increased; however, latent period was unaffected. Parlevliet (25) states that incubation period and latent period tend to "vary in a parallel way". Logically, the increase in incubation period should have been mirrored by a corresponding increase in latent period. Sample size or the timing of evaluations may have biased the estimates, because evaluations were made on a $24-\mathrm{h}$ basis, and lesions that sporulated a few hours after an evaluation would have been recorded as sporulating a day later, thereby inflating the latent period. A larger sample size or more frequent evaluations within a $24-\mathrm{h}$ period could provide a more accurate estimate of incubation and latent period, but were not practical for this study.

Some inferences about the mechanisms by which $\mathrm{Si}$ acts to reduce blast can be drawn from this study. The reduced number of sporulating lesions (relative infection efficiency) on partially resistant and susceptible cultivars fertilized with calcium silicate indicates there were fewer successful infections established per unit of inoculum, lending credence to theories that $\mathrm{Si}$ forms a physical or chemical barrier to penetration $(14,31,43)$. The reductions in the total number of lesions from 0.018 to $0.005 \mathrm{~mm}^{2}$ of leaf area as the rate of $\mathrm{Si}$ increased from 0 to $10 \mathrm{~T} \mathrm{ha}^{-1}$ indicates that $\mathrm{Si}$ manifests its effect before the penetration peg of $M$. grisea actually enters the epidermis, or soon thereafter, indicative of blockage to ingress by the pathogen.

Data collected from controlled tests in the greenhouse on the effects of Si on the severity of blast paralleled that collected from field studies with resistant, partially resistant, and susceptible cultivars of rice (32). In those studies, the amount of disease on partially resistant cultivars grown in the presence of Si could be reduced to levels similar to those observed on resistant cultivars grown in nonamended soils. In the present study, Si effectively raises the apparent level of resistance in partially resistant 'Lemont' to that of the resistant cultivar.

The results from this study underscore the importance of $\mathrm{Si}$ in resistance to rice blast, particularly for partially resistant and susceptible cultivars. The cultivars used in this study came from breeding programs in the southeastern United States and were developed on Si-rich mineral soils. When 'Lemont', 'Rosemont', and 'M201' were grown on a Si-deficient soil without further amendment with calcium silicate, levels of disease were considerably higher than for the same cultivars treated with various levels of calcium silicate. Breeders who are developing cultivars for use in upland rice ecosystems, or other Si-deficient areas, need to consider the impact of $\mathrm{Si}$ on components of resistance and the effect this might have when cultivars adapted for Si-rich environments are moved into Si-deficient soils. Also, judging from the rate response to calcium silicate observed on the cultivars tested in this study, improved uptake of Si could benefit cultivars grown in areas not deficient in $\mathrm{Si}$. Breeding for increased uptake of $\mathrm{Si}$ might be a means to increase the level of resistance to blast.

\section{ACKNOWLEDGMENTS}

We thank the Conservation, Food, and Health Foundation; Calcium Silicate Corporation; Monsanto; the National Committee for International Science and Education administered by the Research and Scientific Exchange Division, Office of International Cooperation and Development, U.S. Department of Agriculture; U.S. Agency for International Development-Scientific Liaison Officer Program administered by the U.S. Department of Agriculture, Office of International Cooperation and Development; the Centro Internacional de Agricultura Tropical; and the University of Florida for financial and operational support.

\section{LITERATURE CITED}

1. Bastiaans, L., Rabbinge, R., and Zadoks, J. C. 1994. Understanding and modeling leaf blast effects on crop physiology and yield. Pages 357-380 in: Rice Blast Disease. R. S. Ziegler, S. A. Leong, and P. S. Teng, eds. CAB International, Wallingford, U.K.

2. Berger, R. D., Bergamin Filho, A., and Amorim, L. 1997. Lesion expansion as an epidemic component. Phytopathology 87:1005-1013.

3. Bonman, J. M. 1992. Blast. Pages 14-16 in: Compendium of Rice Diseases. R. K. Webster and P. S. Gunnel, eds. The American Phytopathological Society, St. Paul, MN.

4. Bonman, J. M., Estrada, B. A., and Bandong, J. A. 1989. Leaf and neck blast resistance in tropical lowland rice cultivars. Plant Dis. 73:388-390.

5. Bonman, J. M., Estrada, B. A., and Kim, D. S. 1991. Assessment of blast disease and yield loss in susceptible and partially resistant cultivars in two irrigated lowland environments. Plant Dis. 75:462-466.

6. Carver, T. L. W., Zeyen, R. J., and Ahlstrand, G. G. 1987. The relation- 
ship between insoluble silicon and success or failure of attempted primary penetration by powdery mildew (Erysiphe graminis) germlings on barley. Physiol. Mol. Plant Pathol. 31:133-148.

7. Castano, J., Mackenzie, D. R., and Nelson, R. R. 1989. Components analysis of race non-specific resistance to blast disease of rice caused by Pyricularia oryzae. J. Phytopathol. 127:89-99.

8. Cherif, M., Asselin, A., and Belanger, R. R. 1994. Defense responses induced by soluble silicon in cucumber roots infected by Pythium spp. Phytopathology 84:236-242.

9. Chiteka, Z. A., Gorbet, D. W., Shokes, F. M., Kucharek, T. A., and Knauft, D. A. 1988. Components of resistance to late leafspot in peanut. I. Levels and variability-implications for selection. Peanut Sci. 15:25-30.

10. Correa-Victoria, F. J., and Zeigler, R. S. 1993. Pathogenic variability in Pyricularia grisea at a rice blast "hot spot" breeding site in eastern Colombia. Plant Dis. 77:1029-1035.

11. Correa-Victoria, F. J, and Zeigler, R. S. 1995. Stability of partial and complete resistance in rice to Pyricularia grisea under rainfed upland conditions in eastern Colombia. Phytopathology 85:977-982.

12. Datnoff, L. E., Snyder, G. H., and Deren, C. W. 1992. Influence of silicon fertilizer grades on blast and brown spot development and on rice yields. Plant Dis. 76:1011-1013.

13. Datnoff, L. E., Snyder, G. H., Raid, R. N., and Jones, D. B. 1991. Effect of calcium silicate on blast and brown spot intensities and yields of rice. Plant Dis. 75:729-732.

14. Elawad, S. H., and Green, V. E. 1979. Silicon and the rice plant environment: A review of recent research. Il Riso 28:235-253.

15. Elliot, C. L., and Snyder, G. H. 1991. Autoclave-induce digestion for the colorimetric determination of silicon in rice straw. J. Agric. Food Chem. 39:1118-1119.

16. Ferreira, S. A., and Webster, R. K. 1975. Genetics of stem rot resistance in rice and virulence in Sclerotium oryzae. Phytopathology 65:968-971.

17. Inanaga, S., Okasaka, A., and Tanaka, S. 1995. Does silicon exist in association with organic compounds in rice plant? Soil Sci. Plant Nutr. 11:111-117.

18. Johnson, D. A., and Wilcoxson, R. D. 1978. Components of slow-rusting in barley infected with Puccinia hordei. Phytopathology 68:1470-1474.

19. Marchetti, M. A. 1983. Dilatory resistance to rice blast in USA rice. Phytopathology 73:645-649.

20. Menzies, J. G., Ehret, D. L., Glass, A. D. M., Helmer, T., Koch, C., and Seyward, F. 1991. Effects of soluble silicon on the parasitic fitness of Sphaerotheca fuliginea on Cucumis sativus. Phytopathology 81:84-88.

21. Menzies, J. G., Ehret, D. L., Glass, A. D. M., and Samuels, A. L. 1991. The influence of silicon on cytological interactions between Sphaerotheca fuliginea and Cucumis sativus. Physiol. Mol. Plant Pathol. 39:403-414.

22. Ohm, H. W., and Shaner, G. E. 1976. Three components of slow leafrusting at different growth stages in wheat. Phytopathology 66:1356-1360.

23. Osuna-Canizalez, F. J., De Datta, S. K., and Bonman, J. M. 1991. Nitrogen form and silicon nutrition effects on resistance to blast disease of rice. Plant Soil 135:223-231.

24. Ou, S. H. 1985. Rice Diseases. 2nd ed. Commonw. Agric. Bur., Kew, England.

25. Parlevliet, J. 1979. Components of resistance that reduce the rate of epidemic development. Annu. Rev. Phytopathol. 17:203-222.

26. Ringer, C. E., and Grybauskas, A. P. 1995. Infection cycle components and disease progress of gray leaf spot on field corn. Plant Dis. 79:24-28.

27. Rodriguez, M., and Galvez, G. E. 1975. Indications of partial resistance of rice to the fungus Pyricularia oryzae Cav. Pages 137-154 in: Proc. Sem. Horizontal Resis. Blast Dis. Rice. G. E. Galvez, ed. Centro Internacional de Agricultura Tropical, Cali, Colombia.

28. Roumen, E. C. 1993. Partial resistance in rice blast and how to select for it. Ph.D. diss. Wageningen Agricultural University, the Netherlands.

29. Roumen, E. C., Bonman, J. M., and Parlevliet, J. E. 1992. Leaf age related partial resistance to Pyricularia oryzae in tropical lowland rice cultivars as measure by the number of sporulating lesions. Phytopathology 82:1414-1417.

30. Rufty, C. R., and Main, C. E. 1989. Components of partial resistance to blue mold in six tobacco genotypes under controlled environmental conditions. Phytopathology 79:606-609.

31. Savant, N. K., Snyder, G. H., and Datnoff, L. E. 1997. Silicon management and sustainable rice production. Adv. Agron. 58:151-199.

32. Seebold, K. W. 1998. The influence of silicon fertilization on the development And control of blast, caused by Magnaporthe Grisea (Hebert) Barr, in upland rice. Ph.D. diss. University of Florida, Gainesville.

33. Seebold, K., Datnoff, L., Correa-Victoria, F., and Kucharek, T. 1997. Effects of silicon and fungicide timing on foliar disease control and yield in upland rice. (Abstr.) Phytopathology 87(suppl.):S87.

34. Seebold, K., Datnoff, L., Correa, F., Kucharek, T., and Snyder, G. 1998. Effects of silicon fertilization and fungicides on epidemics of leaf and neck blast in upland rice in eastern Colombia. (Abstr.) Phytopathology 88(suppl.):S126.

35. Seebold, K., Datnoff, L., Correa, F., Kucharek, T., and Snyder, G. 1998. Effects of silicon and host resistance on leaf and neck blast in upland rice. (Abstr.) Phytopathology 88(suppl.):S80.

36. Shaner, G. 1973. Reduced infectability and inoculum production as factors of slow mildewing in knox wheat. Phytopathology 63:1307-1311.

37. Thurston, H. D. 1984. Rice. Pages 24-30 in: Tropical Plant Diseases. The American Phytopathological Society, St. Paul, MN.

38. van der Plank, J. E. 1963. Plant Diseases: Epidemics and Control. Academic Press, New York.

39. van der Plank, J. E. 1975. Principles of Plant Infection. Academic Press, New York.

40. Volk, R. J., Kahn, R. P., and Weintraub, R. L. 1958. Silicon content of the rice plant as a factor in influencing its resistance to infection by the rice blast fungus, Pyricularia oryzae. Phytopathology 48:121-178.

41. Watson, R. G. 1987. Levels and components of resistance to late leafspot caused by Cercosporidium personatum (Berk. and Curt.) Deighton in the peanut (Arachis hypogaea L.) genotypes Florunner, Southern Runner, and UF81206. Ph.D. diss. University of Florida, Gainesville.

42. Yeh, W. H., and Bonman, J. M. 1986. Assessment of partial resistance to Pyricularia oryzae in six rice cultivars. Plant Pathol. 35:319-323.

43. Yoshida, S., Ohnishi, Y., and Kitagishi, K. 1962. Chemical forms, mobility, and deposition of silicon in the rice plant. Soil Sci. Plant Nutr. 8:107-111.

44. Zeigler, R. S., Tohme, J., Nelson, R., Levy, M., and Correa-Victoria, F. J. 1994. Lineage exclusion: A proposal for linking blast population analysis to resistance breeding. Pages 267-292 in: Rice Blast Disease. R. S. Ziegler, S. A. Leong, and P. S. Teng, eds. CAB International, Wallingford, U.K 